\section{Ingrowing Toenails}

Patients with ingrowing toenails would be surprised to learn that there is no agreed method of treating such a common condition. Indeed, policies range from a conservative regimen to surgery as radical as amputation of the toe. The symptoms of ingrowing toenail are due to soft-tissue damage and sepsis secondary to the abnormality of the nail. Failure to trim the toenail transversely often leads to a damaged nail with a sharp edge. Excessive sweating, tight footwear, and a high arched nail are contributory factors, and recently $H$. $P$. Kopell and his colleagues ${ }^{1}$ have described an abnormality of the bony configuration of the distal phalanx which they claim causes doming of the nail and encourages breakdown of soft tissue. Sepsis perpetuates the condition and leads to the formation of proliferative granulations. The aetiology of onychogryphosis is not clear, but nail bed trauma is thought to play a part.

With perseverance by both patient and doctor conservative treatment of the ingrowing toenail can succeed even in advanced cases complicated by granulations and ragged nails. R. W. Lloyd-Davies and G. C. Brill ${ }^{2}$ recommend careful foot toilet, correct transverse nail trimming, and gentle elevation of the nail and abduction of the nail folds with wool together with excision or silver nitrate cauterization of the granulations. Thick, hard, curved onychogryphotic nails can be treated either by regular chiropody or simple nail avulsion.

Ablation of the nail bed is indicated if conservative measures fail, when the patient has troublesome symptoms despite multiple nail avulsions, or where the nail is deformed owing to trauma to the nail bed.

The limited excision of the germinal matrix was originally described by E. A. V. A. Quénu. ${ }^{3}$ A skin flap is raised at the base of the nail, the major source of nail growth, and an area overlying the base of the terminal phalanx is excised together with the nail folds. In the Syme operation ${ }^{4}$ the whole bed of the nail is removed and the distal half of the terminal phalanx is amputated. The name Syme is attached to the procedure because a long flap of plantar skin is brought up over the end of the bone, as in the classical Syme amputation at the ankle joint.

Ablation of the nail bed cannot be carried out if the toe is infected. Preliminary avulsion of the nail may therefore be necessary, ${ }^{5}$ but it makes the subsequent ablation operation more difficult as the distal edge of the lunula, which marks the limits of the germinal matrix, becomes obscured. This may be one cause of the regrowth of the nail found by several authors.

F. R. Zadik ${ }^{6}$ and A. W. Fowler ${ }^{7}$ both found the limited operation highly successful, while Lloyd-Davies ${ }^{8}$ and R. W. M. Rees ${ }^{9}$ reported unsatisfactory results-mostly related to regrowth of the nail rather than symptoms. A. C. Townsend and P. J. Scott ${ }^{4}$ report satisfactory results in $89 \%$ of 64 toes operated on by Zadik's technique. Although minor degrees of regrowth of the nail followed $50 \%$ of these ablations, this regrowth was accompanied by little in the way of symptoms. These results are as good as those

\footnotetext{
' Kopell, H. P., Winokur, J., and Thompson, W. A. L., N.Y. St. F. Med., $1966,66,1215$.

${ }^{2}$ Lloyd-Davies, R. W., and Brill, G. C., Brit. F. Surg., 1963, 50, 592.

Quénu, E. A. V. A., Bull. Soc. Méd. Paris, 1887, 13, 255.

Thompson, T. C., and Terwilliger, C., Surg. Clin. N. Amer., 1951, 31, 575 .

- Townsend, A. C., and Scott, P. J., f. Bone ft Surg., 1966, 48B, 354.

- Zadik, F. R., ibid., 1950, 30B, 66.,

Fowler, A. W., Brit. F. Surg., 1958, 45, 382.

- Lloyd-Davies, R. W., ibid., $1962,50,44$.

- Rees, R. W. M., Proc. roy. Soc. Med., 1964, 57, 355.
}

after the Syme operation and avoid the short misshapen toe. ${ }^{8}$

Most operations for ablation of the nail bed will succeed, but good results cannot be obtained unless the surgeon is interested in this problem and therefore takes the pains necessary to carry out the procedure correctly. Certainly these are not operations for the inexperienced house-surgeon at the end of a long list.

\section{Genetics of Juvenile Diabetes Mellitus}

The inheritance of juvenile diabetes mellitus - that is, diabetes with an onset under the age of $15-$ is complex. H. Harris ${ }^{1}$ suggested some years ago that such children were homozygotes for a gene which in heterozygotes predisposed to the onset of diabetes in adult life. Even the homozygotes could only be predisposed to the disease, for the proportion of sibs actually affected by it is substantially less than one in four. With certain relatively rare types of diabetes mellitus the evidence for recessive inheritance is better. Thus diabetes mellitus may accompany the autosomal recessive syndrome Refsum's disease (heredopathia atactica polyneuritiformis), and a syndrome described by C. H. Alström and colleagues ${ }^{2}$ in which the patient has optic atrophy secondary to retinal degeneration, severe perceptive deafness, and obesity. Optic atrophy also occurs with diabetes mellitus in a minority of cases of Friedreich's ataxia, and also in the syndrome of diabetes insipidus, juvenile diabetes mellitus, and optic atrophy. ${ }^{3}$

F. C. Rose and his colleagues ${ }^{4}$ have assembled from schools and welfare organizations for the blind in England and Wales seven patients, all males, two of whom were brothers, with juvenile diabetes and primary optic atrophy. Several patients were ascertained from more than one source, suggesting that probably nearly all cases in the country were picked up in the survey, provided the optic atrophy was sufficient to cause blindness.

One patient had only optic atrophy and juvenile diabetes mellitus ; his parents were first cousins once removed. Three patients had in addition some deafness. A fifth patient in addition showed evidence of cortical atrophy of the brain. A sixth showed evidence of diffuse involvement of the central nervous system, and the features of this case were compatible with some of the varieties of Friedreich's ataxia; the parents of this patient were first cousins. The seventh case belonged to the syndrome described by Alström and his colleagues. Other single cases have been reported in the literature, several of them having a history of similarly affected sibs. In these reported cases there is a preponderance of females, suggesting that the limitation to males in the present series is fortuitous.

The authors suggest that their cases are homozygous for recessive genes but that the clinical variation may be due to several different mutant genes causing the syndrome. The frequency of the association of juvenile diabetes mellitus and optic atrophy suggests that there must be some biochemical link between the disturbance causing the optic atrophy and the early onset of diabetes mellitus.

\footnotetext{
" Harris, H., Ann. Eugen. (Lond.), 1950, 15, 95. psychiat. scand., 1959, 34, Suppl. No. 129.

3 Raiti, S., Plotkin, S., and Newns, G. H., Brit. med. Y., 1963, 2, 1625.

Rose, F. C., Fraser, G. R., Friedmann, A. I., and Kohner, E. M., Quart. f. Med., 1966, 35, 385.
} 